\title{
IDENTIFIKASI FAKTOR PENYEBAB DEFECT PRODUKSI KANTONG SEMEN SERTA COST INTERNAL FAILURE YANG DITIMBULKAN PADA PT. SEMEN PADANG
}

\author{
Dedi Dermawan $^{1}$, Nelfiyanti ${ }^{1}$, Japri ${ }^{2}$ \\ 1. Program Studi Teknik Industri Universitas Muhammadiyah Riau \\ 2. Program Studi Teknik Otomotif Universitas Muhammadiyah Riau \\ e-mail: dedi_dermawan1905@yahoo.com
}

\begin{abstract}
ABSTRAK
Divisi Pabrik Kantong merupakan divisi yang diberi tanggung jawab oleh PT. Semen Padang dalam memproduksi sejumlah kantong semenPenelitian dilakukan untuk mengidentifikasi faktor-faktor kritis (CTQ) yang berpengaruh terhadap timbulnya cacat hasil longitudinal glue tidak merata dan kuat dengan menggunakan pendekatan Quality yaitu menggunakan pendekatan Define dan Measure. Faktor yang telah diidentifikasi, didapatkan faktor yang berpengaruh terhadap karakteristik kualitas $(C T Q)$ sehingga dapat diketahui Tingkat Kapabilitas produksi dari kantong semen tersebut. Dampak yang diperoleh dari defect yang terjadi menimbulkan biaya kegagalan internal (Cost Internal Failure) yang semakin besar, sehingga mengakibatkan Biaya pokok produksi meningkat.
\end{abstract}

Kata Kunci: $\quad$ Define, Measure, CTQ (Critical To Quality), Cost Internal Failure.

\section{PENDAHULUAN}

Perbaikan kualitas yang berkesinambungan (continuous quality improvement) merupakan suatu hal yang mesti dilakukan bagi setiap Industri untuk tetap bertahan hidup dalam persaingan yang serba kompetitif saat ini. Permasalahan pemasaran dan produksi selalu menjadi hal yang komplek didalam perjalanan manajemen sebuah Industri baik manufaktur maupun jasa. PT. Semen Padang. Divisi Pabrik Kantong mempunyai peranan penting untuk memproduksi sejumlah kantong bagi konsumen. Namun kendala didalam pencapaian jumlah produksi kantong yang optimal dan kesesuaian dengan spesifikasi yang dibutuhkan oleh konsumen menjadi suatu hambatan dari pihak pabrik didalam memproduksinya. Berikut Produk cacat (defect) pada proses pembuatan kantong yang di identifikasi dari lantai produksi yang tidak memenuhi spesifikasi seperti: (a) Hasil printing cacat pada tube sewing dan tube paste, (b) Hasil longitudinal glue tidak merata dan kuat, (c) Hasil potong dari cutting unit tidak sempurna dan atau tidak terpisah, yaitu terjadinya pemotongan yang tidak simetris terhadap kantong yang akan dilakukan penjahitan (tube).

\section{METODOLOGI PENELITIAN}

Kerangka pemecahan masalah melalui tahap-tahap penelitian yang sistematis meliputi:

\section{Pemecahan Masalah}

Tahapan Implementasi secara sistematis dari pendekatan Define dan Measure berdasarkan konsep mutu untuk memperoleh tujuan dari pada penelitian adalah sebagai berikut: 


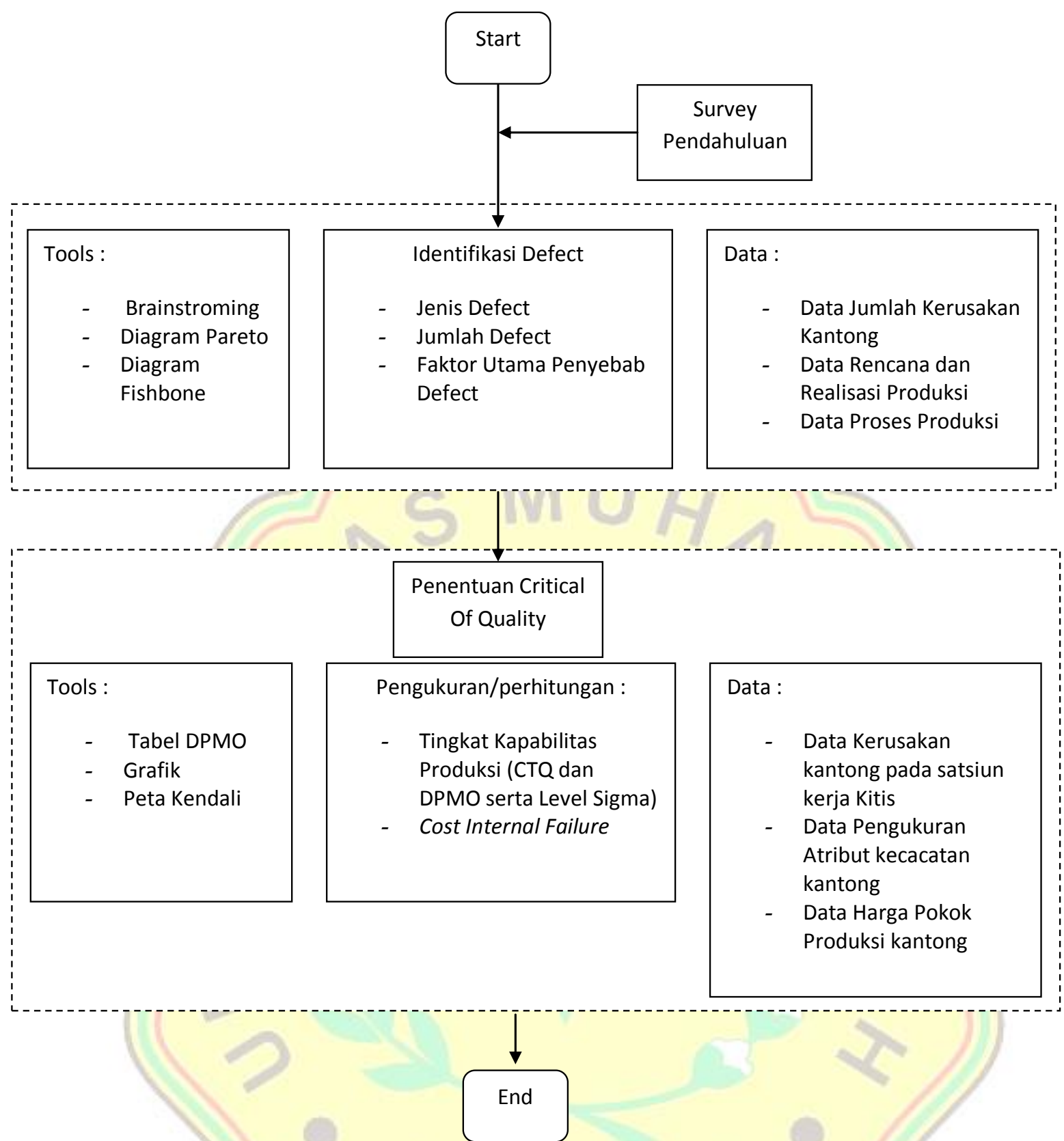

Gambar 1. Kerangka Pemecahan Masalah

Tahap Define:Define merupakan langkah pertama dalam peningkatan kualitas dengan Six Sigma, pada tahap ini dilakukan beberapa hal yang penting.

Perumusan Masalah. :Masalah yang akan diidentifikasikan disini berasal dari data produksi kantong semen pada bulan Januari hingga Juni 2007. Berdasarkan laporan Mutu produksi kantong semen pada bulan Januari hingga Juni terdapat jumlah kantong semen yang tidak berkesesuaian sangat besar sekali jumlahnya.
Jenis produk yang tidak berkesesuaian pada proses Tubing sbb:

1. Hasil printing cacat pada tube

2. Hasil longitudinal glue tidak merata dan kuat.

3. Hasil potong dari cutting unit tidak sempurna atau tidak terpisah

Grafik Kerusakan kantong Proses Tubing Januari hingga Juni 2007 Divisi Pabrik Kantong PT. Semen Padang adalah sebagai berikut: 


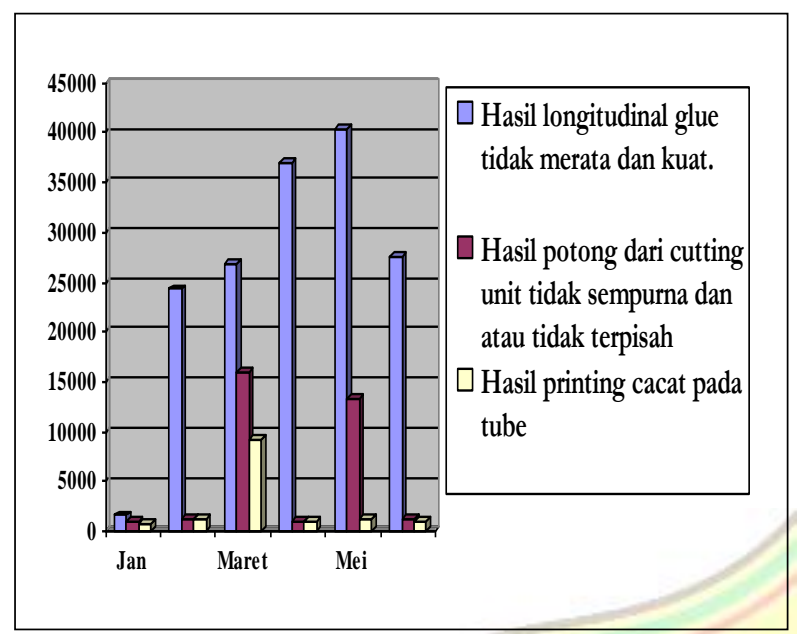

Gambar 2. Kantong yang tak berkesesuian

Berikut Diagram Pareto kantong semen pada Proses Tubing yang tak berkesesuian terjadi:

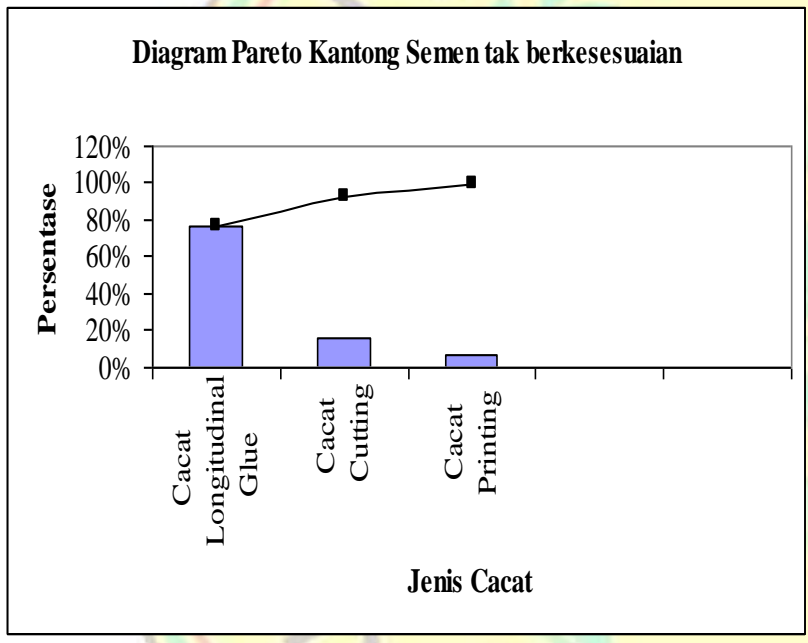

Gambar 3. Diagram Pareto Persentase dan Jenis Cacat pada Kantong semen

Fokus permasalahan yang diangkat adalah hasil cacat longitudinal glue. Hal tersebut didasarkan atas pertimbangan sebagai berikut:

1. Hasil cacat longitudinal glue adalah cacat dominan atau jenis cacat yang sering muncul.

2. Penyebab-penyebab terjadinya cacat dapat diamati dan diukur.

3. Dapat dilakukan perbaikan dengan melakukan percobaan.

Penentuan Penyebab Umum Terjadinya Cacat.
Berdasarkan hasil observasi lapangan dan konsultasi dengan operator, didapatkan faktor-faktor yang mempengaruhi terjadinya Cacat Longitudinal yang tergambar dalam bentuk diagram sebab akibat (Fishbone Diagram) sebagai berikut:

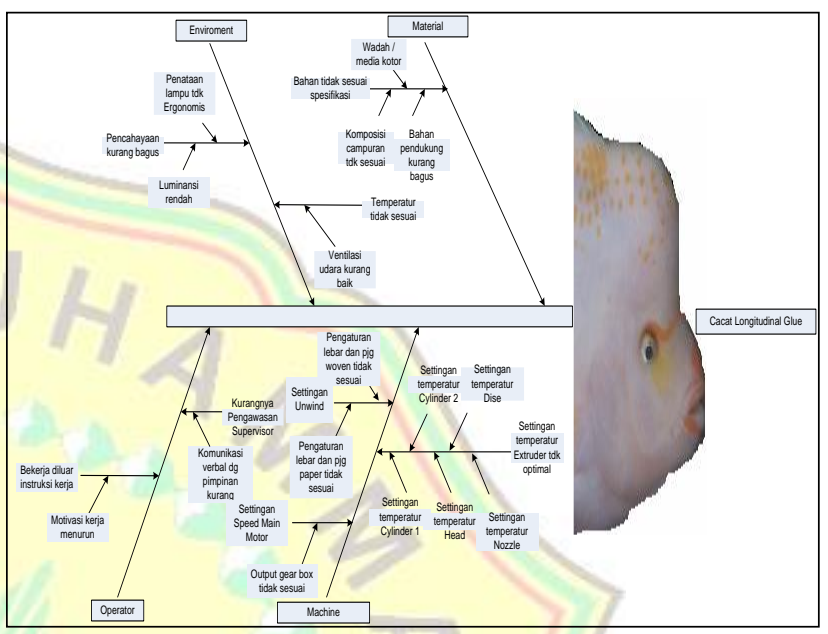

Gambar 4. Diagram Fishbone

Tahap Measure

Penentuan CTQ Proses Produksi.

Penentuan titik kritis (CTQ = Critical To Quality) yang akan digunakan untuk menentukan stasiun kerja kritis yaitu bagian dari proses produksi tempat terjadinya cacat jenis Cacat Longitudinal yang merupakan cacat dominan dalam produksi kantong semen.

\begin{tabular}{ll}
\hline & Karakteritik Kualitas (CTQ) \\
\hline 1. & Pengontrolan kecepatan Main Motor yang tidak optimal \\
2. & Temperatur Extruder yang tidak sesuai.
\end{tabular}

Perhitungan Peta Kendali dengan DPMO.

\section{HASIL DAN PEMBAHASAN}

Berdasarkan penelitian penyebab terjadinya hasil cacat longitudinal glue adalah: settingan Speed Main Motor tidak optimal dan Settingan temperatur Extruder yang tidak sesuai. Maka terdapat 2 CTQ potensial yang menimbulkan cacat pada kantong semen Reinforce laminating. 
Pengukuran secara visual dilakukan terhadap 480 produk sebagai berikut:

Tabel 2. Data Pengukuran Atribut Kecacatan Produk Kantong semen

\begin{tabular}{|c|c|c|c|c|c|}
\hline \multirow{2}{*}{ Pemeriksaan } & \multirow{2}{*}{$\begin{array}{l}\text { Banyalnya } \\
\text { Produk Yang } \\
\text { Diperiksa }\end{array}$} & \multicolumn{2}{|c|}{$\begin{array}{c}\text { Banyalnya } \\
\text { Produk Cacat }\end{array}$} & \multirow{2}{*}{$\begin{array}{c}\text { CTQ } \\
\text { Potensial } \\
\text { Penyebab } \\
\text { Cacat } \\
\end{array}$} & \multirow{2}{*}{$\begin{array}{c}\text { Deskripsi CTQ } \\
\text { Potensial Penyebab } \\
\text { Cacat }\end{array}$} \\
\hline & & 1 & 2 & & \\
\hline 1 & 120 & 2 & 4 & 2 & \multirow{5}{*}{$\begin{array}{l}\text { Settingan Speed } \\
\text { Main Motor tidak } \\
\text { optimal } \\
\text { Settingan } \\
\text { temperatur } \\
\text { Extruderyang tidak } \\
\text { sesuai (2) }\end{array}$} \\
\hline 2 & 120 & 3 & 5 & 2 & \\
\hline 3 & 120 & 2 & 3 & 2 & \\
\hline 4 & 120 & 3 & 4 & 2 & \\
\hline Jumlah & 480 & & & & \\
\hline
\end{tabular}

DPMO dan kapabilitas sigma dari data hasil pengukuran atribut karakteristik kualitas pada tingkat output.

\begin{tabular}{|c|c|c|c|c|c|c|}
\hline \multirow{2}{*}{$\begin{array}{c}\text { Pemerik } \\
\text { saan } \\
\text { (1) }\end{array}$} & \multirow{2}{*}{$\begin{array}{c}\text { Banyaknya } \\
\text { Produk yang } \\
\text { Dipeniksa } \\
\text { (2) }\end{array}$} & \multicolumn{2}{|c|}{$\begin{array}{c}\text { Banyaknya } \\
\text { Produk Cacat } \\
\text { (3) }\end{array}$} & \multirow{2}{*}{$\begin{array}{c}\text { Banyaknya CTQ } \\
\text { Potensial Penyebab } \\
\text { Cacat } \\
\text { (4) }\end{array}$} & \multirow{2}{*}{$\begin{array}{c}\text { DPMO } \\
(5)= \\
{[(3)\{(2) \times(4)\}]} \\
\times 1.000 .000\end{array}$} & \multirow[t]{2}{*}{$\begin{array}{c}\text { Sigm } \\
\text { a }\end{array}$} \\
\hline & & 1 & 2 & & & \\
\hline 1 & 120 & 2 & 4 & 2 & 25000 & 3,46 \\
\hline 2 & 120 & 3 & 5 & 2 & 33333 & 3,33 \\
\hline 3 & 120 & 2 & 3 & 2 & 20833 & 3,53 \\
\hline 4 & 120 & 3 & 4 & 2 & 29167 & 3,39 \\
\hline Jumlah & 480 & & & & 27083 & 3,42 \\
\hline
\end{tabular}

Berbagai nilai DPMO dan kapabilitas sigma apabila ditebarkan ke dalam grafik akan tampak seperti dalam gambar berikut:

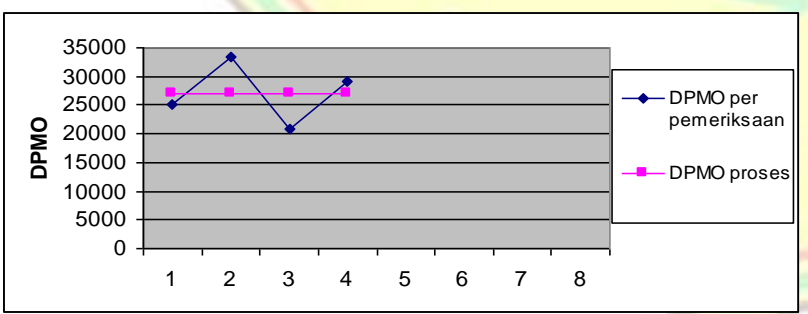

Gambar 5. Pola DPMO Produk Kantong semen

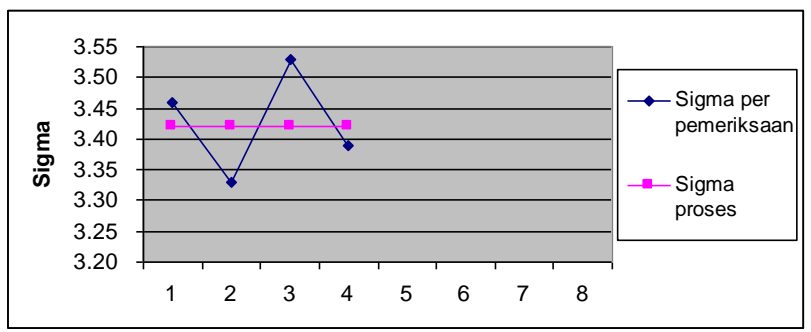

\section{Gambar 6. Pola Nilai Kapabilitas Sigma}

Proses Produksi Kantong semen

Grafik di atas menunjukkan pola DPMO dari kegagalan produk kantong semen dan pencapaian sigma yang belum konsisten, masih bervariasi naik turun sepanjang periode pengamatan, sekaligus menunjukkan bahwa proses produksi kantong semen belum dilakukan secara tepat.

Peta kontrol digunakan untuk melihat proporsi cacat pada penelitian apakah masih dalam batas kontrol atau tidak. Peta kontrol yang digunakan yaitu peta-P yang merupakan peta kontrol atribut. Dipilih peta$P$ karena data yang didapat dari hasil penelitian berupa cacat (nonconformities) dengan jumlah sampel sama setiap kali penelitian yaitu 120 buah. Berikut ini adalah data dan hasil perhitungan cacat.

- Proporsi cacat (p)

$$
\mathrm{P}=\frac{x}{n}
$$

- Garis pusat $(\mathrm{CLp}=\mathrm{p})$

CLp

$$
p \frac{\sum_{i=1}^{g} P i}{g}=\frac{\sum_{i=j}^{g} X i}{n g}=\frac{26}{480}=0.054
$$

- Garis Batas Kontrol Atas (UCL)

$$
\begin{aligned}
\text { UCLp } & =p+3 \sqrt{\frac{p(1-p)}{n}} \\
& =0,054+3 \sqrt{\frac{0,054(1-0,054)}{120}} \\
& =0,0116
\end{aligned}
$$

- Garis Batas Kontrol Bawah atau (LCL)

$$
\begin{aligned}
\mathrm{LCLp} & =\mathrm{p}-3 \sqrt{\frac{p(1-p)}{n}} \\
& =0,054-3 \sqrt{\frac{0.054(1-0.054)}{120}} \\
& =-0.0078
\end{aligned}
$$


Tabel 4. Data dan Hasil Perhitungan Cacat

\begin{tabular}{|c|c|c|c|c|c|}
\hline Pemerksaan & $\begin{array}{c}\text { Banyaknya } \\
\begin{array}{c}\text { Produk yang } \\
\text { Diperiksa } \\
(\mathrm{n})\end{array}\end{array}$ & $\begin{array}{c}\text { Banyaknya } \\
\text { Produk Cacat } \\
(\mathrm{x})\end{array}$ & $\begin{array}{c}\text { Proporsi } \\
\text { Cacat } \\
(\mathrm{p})\end{array}$ & UCL & ICL \\
\hline 1 & 120 & 6 & 0,042 & \multirow{2}{*}{0,116} & \multirow{2}{*}{0.0078} \\
\hline 2 & 120 & 8 & 0,067 & \\
\hline 3 & 120 & 5 & 0,058 & & \\
\hline 4 & 120 & 7 & 0,05 & & \\
\hline Jumlah & 480 & 26 & 0,054 & 0,116 & 0 \\
\hline
\end{tabular}

Berdasarkan data dan hasil perhitungan cacat di atas, kemudian dibuat peta proporsi Cacat Longitudinal untuk mengetahui apakah sampel yang diambil berada dalam batas kontrol atau tidak.

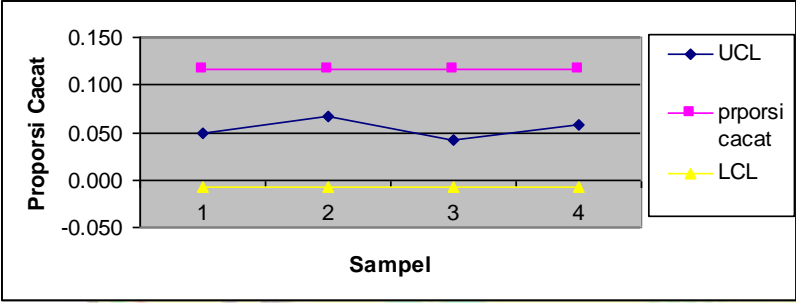

Gambar 7. Peta Proporsi Cacat Kantong semen

Berdasarkan peta kontrol di atas terlihat bahwa proses saat ini berada di dalam kendali. Karena semua sampel berada di dalam batas kontrol, maka nilai DPMO dan kapabilitas sigma proses dapat digunakan sebagai ukuran kemampuan proses yang sesungguhnya, sekaligus merupakan baseline kinerja untuk peningkatan selanjutnya.

Identifikasi Kategori Biaya Kegagalan Kualitas.

Unsur-unsur biaya kegagalan kualitas dapat diidentifikasi dari analisa terhadap beberapa biaya yang dikeluarkan oleh perusahaan. Biaya kegagalan kualitas pada pabrik kantong semen terdiri dari biaya kegagalan internal.

Biaya Kegagalan Internal

Biaya kegagalan internal merupakan ketidaksesuaian dengan persyaratan atau spesifikasi kualitas yang telah ditetapkan, namun sudah dapat dideteksi sebelum produk sampai ke tangan konsumen. Yang termasuk kegagalan dari biaya internal adalah dalam proses Tubing sesuai dengan identifikasi awal unit yang menjadi faktor dominan penyebab munculnya produk yang tidak berkesesuaian yaitu pada unit longitudinal glue.

Maka dapat diperoleh perhitungan Biaya Kegagalan Internal untuk masing-masing type kantong yang terjadi selama produksi periode Januari sampai dengan Juni 2007 sebagai berikut:

\section{KESIMPULAN}

- Berdasarkan data penelitian diketahui data produksi Divisi Pabrik Kantong memproduksi kantong rata-rata setiap bulan 1.138.755 helai, sedangkan jumlah defect dalam produksi kantong semen diperkirakan secara kamulatif terjadi setiap bulan rata-rata mencapai 33.971 helai. Hal ini mengakibatkan pemborosan biaya yang sangat besar setiap bulannya., berarti pemborosan biaya untuk produk cacat tersebut mencapai sekitar 2,97\% rata-rata setiap bulannya

- Pemecahan masalah dilakukan dengan pendekatan sbb:

1. Tahap Define: Cacat dominan yang diteliti adalah cacat hasil Longitudinal Glue

2. Tahap Measure: Penentuan CTQ yang diperoleh dari Fishbone Diagram yaitu settingan speed Main Motor yang tidak optimal, dan settingan temperature Extruder yang tidak sesuai. Pengukuran baseline kinerja pada tingkat output didapatkan nilai DPMO yaitu 27083 dengan tingkat level Sigma yang dicapai adalah 3,42.

- Sedangkan Total Biaya Kegagalan Internal untuk produksi Kantong 
periode Januari hingga Juni tahun 2007 diperoleh sbb:

\begin{tabular}{|l|l|}
\hline \multicolumn{1}{|c|}{ Jenis } & \multicolumn{1}{|c|}{$\begin{array}{c}\text { Biaya Kegagalan } \\
\text { Internal (Rp) }\end{array}$} \\
\hline $\begin{array}{l}\text { Kantong Jahit Kraft paper } \\
40 \mathrm{~kg}\end{array}$ & $37,191,732.55$ \\
\hline $\begin{array}{l}\text { Kantong Jahit Kraft paper } \\
50 \mathrm{~kg}\end{array}$ & $68,772,755.32$ \\
\hline $\begin{array}{l}\text { Kantong Jahit Reinforce } \\
\text { Laminating 40 kg }\end{array}$ & $22,040,015.76$ \\
\hline $\begin{array}{l}\text { Kantong Jahit Reinforce } \\
\text { Laminating 50 kg }\end{array}$ & $504,747,560.51$ \\
\hline Total & $\mathbf{6 3 2 , 7 5 2 , 0 6 4 . 1 4}$ \\
\hline
\end{tabular}

\section{DAFTAR PUSTAKA}

Belavendram, N, 1995, Quality By Design,

Prentice Hall International (UK) Limited, London.

Juran, Joseph M dan Godfrey A. Blanton, 1999, Jurans Quality Hanbook, 5th ed, McGraw-Hill

Paul A. Keller, 2003, Quality Engineering
Handbook, Second Edition, Marcel Dekker, Inc.

John S, Oakland, 2003, Statistical Process Control, Fifth Edition ButterworthHeinemann An imprint of lsevier Science Linacre House, Jordan Hill, Oxford

Truscott William. T, Six Sigma Continual Improvement for Businesses, A Practical Guide, ButterworthHeinemann, Newgen Imaging Systems (P) Ltd, Chennai, India

U, Dinesh Kurnar, at all, Reliability and Six Sigma, 2006, Springer Science Business Media, Inc.

Michael E. Ginevan Douglas E. Splitstone, Statistical Tools For Environmental Quality Measurement, 2003, A CRC Press Company Boca Raton London, New York Washington, D.C. 